\title{
Detection of trace levels of lead in aqueous liquids using extractive electrospray ionization tandem mass spectrometry
}

\author{
Chunxiao Liu $^{\mathrm{a}, 1}$, Xinglei Zhang ${ }^{\mathrm{b}, 1}$, Saijin Xiao ${ }^{\mathrm{b}}$, Bin Jia ${ }^{\mathrm{b}}$, Shasha Cui ${ }^{\mathrm{b}, \mathrm{c}}$, Jianbo Shi ${ }^{\mathrm{a}}$, \\ Ning Xu ${ }^{\mathrm{b}}$, Xi Xie ${ }^{\mathrm{d}}$, Haiwei Gu ${ }^{\mathrm{b}, *}$, Huanwen Chen ${ }^{\mathrm{b}}$

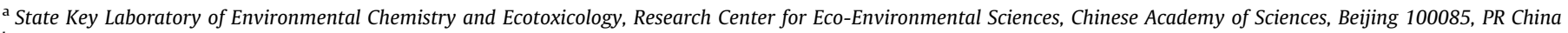 \\ b Jiangxi Key Laboratory for Mass Spectrometry and Instrumentation, East China Institute of Technology, Nanchang, Jiangxi Province 330013, PR China

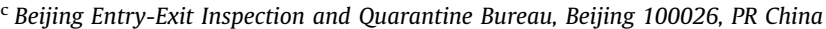 \\ 'The Administrative Centre for China's Agenda 21(ACCA21), Beijing 100038, PR China
}

\section{A R T I C L E I N F O}

\section{Article history:}

Received 22 March 2012

Received in revised form

14 June 2012

Accepted 20 June 2012

Available online 26 June 2012

Keywords:

Extractive electrospray ionization

Ambient mass spectrometry

Tandem mass spectrometry

Lead

Beverage

\begin{abstract}
A B S T R A C T
A sensitive approach, based on semi-quantitative measurement of the characteristic fragments in multistage extractive electrospray ionization mass spectrometry $\left(\right.$ EESI-MS ${ }^{n}$ ), was developed for fast detection of trace levels of lead in aqueous liquids including mineral water, lake water, tap water, energy drinks, soft drinks, beer, orange juice, and tea. A disodium ethylene-diamine-tetraacetic acid (EDTA) aqueous solution was electrosprayed to produce negatively charged primary ions which then intersected the neutral sample plume to generate anions of EDTA-Pb(II) complexes. The charged EDTA-Pb(II) complexes were characterized with multistage collision induced dissociation (CID) experiments. The limit of detection (LOD) using EESI-MS ${ }^{3}$ was estimated to be at the level of $10^{-13} \mathrm{~g} / \mathrm{mL}$ for directly detecting lead in many of these samples. The linear dynamic range was higher than 2 orders of magnitude. A single sample analysis could be completed within 2 min with reasonable semi-quantitative performance, e.g., relative standard deviations (RSDs) for deionized water were 4.6-7.6\% during 5 experimental runs (each of them had 10 repeated measurements). Coca-cola and Huiyuan orange juice, representative beverage samples with complex matrices, generated recovery rates of $91.5 \%$ and $129 \%$, respectively. Our experimental data demonstrated that EESI-MS is a useful tool for the fast detection of lead in various solutions, and EESI-MS showed promises for fast screening of lead-contaminated aqueous liquid samples.
\end{abstract}

(c) 2012 Elsevier B.V. All rights reserved.

\section{Introduction}

Lead is toxic to human beings beyond a certain exposure level [1-3]. Lead poisoning results from exposure to divalent lead $\mathrm{Pb}(\mathrm{II})$ through inhalation or ingestion. Lead can interfere with a variety of biochemical processes in human bodies, such as inhibiting porphobilinogen synthase and ferrochelatase. The interference consequently may cause severe damages to hearts, bones, intestines, kidneys, and the reproductive and nervous systems [2-8]. A common antidote for lead poisoning is ethylene-diamine-tetracetic acid (EDTA) $[3,9,10]$ because it has a strong affinity for lead to form complexes. Although worldwide atmospheric lead concentration has significantly decreased in the past two decades due to the increasing usage of lead-free gasoline, lead poisoning is still often reported because of contaminated environmental sources including air, dust, food, toys, and beverages [11-14]. Studies have shown that children in some areas of China have a lead level in blood 4 times

\footnotetext{
* Corresponding author. Tel.: +86 79183896370 ; fax: +86 79183896370

E-mail address: guhaiwei2004@gmail.com (H. Gu).

${ }^{1}$ Both authors contributed equally to this work.
}

higher than the WHO's safe limit [15-18]. In the United States, lead poisoning is still the most common disease of environmental origin, annually affecting approximately 250,000 children between the age of $1-5$ years old $[19,20]$. As an important manner of contamination, lead in beverages may come from contaminated water, fruit, land, and cans. Because of their easy contact with internal organs, the estimation of human risk to lead contamination can be performed through monitoring lead in beverages [21-23]. Therefore, it is useful to develop novel approaches for the fast, sensitive, and reliable determination of lead in aqueous liquid samples, not only for environment assessment but also for clinical significance.

Currently, representative techniques for lead detection include colorimetric assay, atomic absorption spectrometry (AAS), atomic emission spectrometry (AES), electrochemistry methods, biosensors, nuclear magnet resonance, and mass spectrometry [24-27]. Inductively coupled plasma mass spectrometry (ICP-MS) has been widely used to detect lead in biological fluids, tissues, environmental samples, and oils [28-35]. However, most traditional analytical techniques do not allow direct analysis of lead especially in complex media. Time-consuming pretreatment procedures are generally required to clean matrices and concentrate analytes before the actual detection. Recently, breakthrough of mass 
spectrometry towards rapid analysis of complex samples was made by Cooks et al. with the invention of desorption electrospray ionization (DESI) [36,37]. After DESI, more than 20 ambient ionization techniques were further developed, including direct analysis in real time (DART) [38,39], surface desorption atmospheric pressure chemical ionization (DAPCI) [40,41], extractive electrospray ionization (EESI) [42], low temperature plasma (LTP) $[43,44]$, and easy ambient sonic ionization (EASI) [45]. Two major advantages of ambient mass spectrometry are minimal sample pre-treatment and high-throughput MS analysis [46-48]. Compared to other ambient ionization methods, EESI has a unique design utilizing two sprayers and aligning them along a certain angle with respect to the mass spectrometer. Neutral droplets from one sprayer can be ionized under ambient conditions by primarily charged droplets generated by the electrospray ionization (ESI) channel. The design of EESI allows samples to be dispersed in a relatively large volume among the neutral channel, the electrospray channel, and the ion inlet of the MS instrument. Therefore, EESI tolerates complex matrices, which makes it a promising alternative to ICP-MS for directly analyzing lead in aqueous liquids. Another merit of EESI is that samples are isolated from the direct bombardment by charged particles or energetic metastable atoms, and thus EESI is a relatively soft ionization method which may help to extract valuable structure information from complexes. EESI has been applied to the rapid characterization of metabolic biomarkers in biological samples [49] and living objects [50,51], trace amounts of explosives on human skin [52], drugs [53], and proteins in solutions [54] with minimal sample pretreatment.

Most of EESI-MS studies have been carried out for the analysis of organic compounds, although the successful detection of uranium and its salts using EESI-MS has been reported [55]. In this study, EESI-MS was used for the fast and sensitive detection of trace levels of lead in aqueous liquid samples. The EDTA aqueous solution was used in the ESI channel so that EDTA-Pb(II) complexes could be generated online in the EESI source to enhance detection selectivity. We further challenged the analysis speed of EESI-MS and examined its quantitative capability for the direct detection of lead in different aqueous liquids.

\section{Materials and methods}

\subsection{Reagents and materials}

Lead(II) acetate trihydrate (analytical grade) was purchased from Tianjin Damao Chemical Reagent Factory (Tianjin, PR China); disodium ethylenediaminetetraacetate dihydrate (analytical grade) was bought from Shantou Xilong Chemical Factory (Shantou, PR China). In-house deionized water was used to make a series of standard solutions with concentrations from $1 \mathrm{ppt}$ to $1 \mathrm{ppm}$ which were prepared by dissolving the corresponding chemicals in the methanol/water (1:1) solution. Some beverages were purchased in local supermarkets including Nongfu Spring mineral water (Zhejiang Province, PR China), Master Kang mineral water (Taiwan), Red Bull (Austria), Qingdao beer (Shandong Province, PR China), Jinggang green tea (Jiangxi Province, PR China), Coca-cola (US), Huiyuan orange juice (Beijing, PR China), and Woolong tea (Guangdong Province, PR China). In addition, lake water (Jiangxi Province, PR China) and tap water (Jiangxi Province, PR China) were also sampled for EESI-MS analysis.

\subsection{EESI-MS experiments}

All experiments were performed using a linear ion trap mass spectrometer (LTQ-XL, Finnigan, San Jose, US) coupled with a homemade EESI source. The EESI source and the LTQ mass

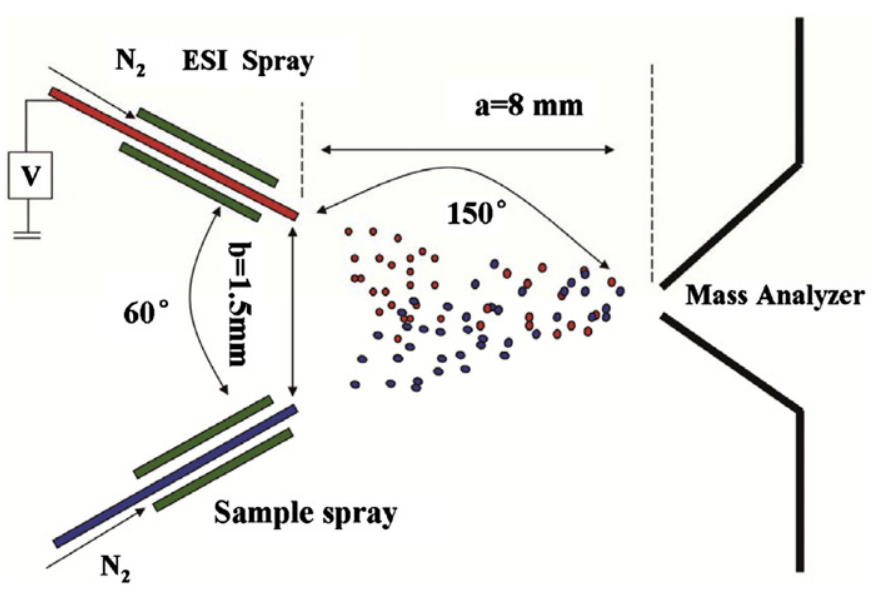

Fig. 1. Schematic illustration of the EESI source for detecting lead in liquids.

spectrometer were set to work in the negative ion detection mode. The EESI source was described previously [56], and herein we only provided a brief description. Fig. 1 is the schematic illustration of the EESI source. The sample channel formed an angle of $60^{\circ}$ with the electrospray beam, and the distance (b) between the two tips was $1.5 \mathrm{~mm}$. The angle between the electrospray beam and the heated capillary of the LTQ instrument, and the angle formed between the sample channel and the heated capillary of the LTQ instrument were both $150^{\circ}$. The EESI assembly was coaxially mounted to the heated capillary of the LTQ instrument; the distance (a) between the inlet of the LTQ instrument and the EESI source was $8 \mathrm{~mm}$. The ESI voltage was $-3.5 \mathrm{kV}$, and a solution of disodium ethylenediaminetetraacetate dihydrate in methanol/water was electrosprayed with an infusion rate of $5 \mu \mathrm{L} / \mathrm{min}$ to produce primary ions. We also tried the ESI solvents with different amounts of acetic acid, and it was found that the currently selected ESI solution is an appropriate choice for this study in terms of qualitative and quantitative EESI-MS measurements. The flow rate for sample infusion was also $5 \mu \mathrm{L} / \mathrm{min}$, and the gas pressure in both channels was $1 \mathrm{MPa}$. The temperature of the heated capillary of the LTQ instrument was maintained at $180^{\circ} \mathrm{C}$. Collision induced dissociation (CID) experiments were performed by applying 18-35\% (manufacturer defined energy unit) collision energy to the precursor ions isolated with a mass/charge window of 1 unit. The default voltages for the heated capillary, ion optics, and detectors were directly used without further optimization. To remove carryover effect, the methanol/water mixture $(1: 1)$ was infused through the sample channel after each analysis until the signal related to lead was reduced to the background level.

\section{Results and discussion}

\subsection{Qualitative characterization}

Selective detection of trace levels of analytes such as cocaine in beverages [57] and diethylene glycol in toothpastes [58] has been demonstrated with EESI tandem mass spectrometry implemented with selective ion/molecule reactions. In this study, EDTA selectively combined with lead in the EESI source because EDTA has a high affinity for $\mathrm{Pb}(\mathrm{II})$. An EDTA solution of $10 \mathrm{ppm}$ was first infused through the ESI channel, and a lead acetate solution of $5 \mathrm{ppm}$ was nebulized towards the electrospray beam, where micro liquid droplet-droplet extraction/ionization occurred. The micro liquid droplet-droplet extraction was proven to play an important role in EESI ionization [59]. Fig. 2 showed a typical EESI-MS spectrum collected from such experiments. The most abundant (major) ion was that of $\mathrm{m} / \mathrm{z} 291.10$ due to deprotonated 


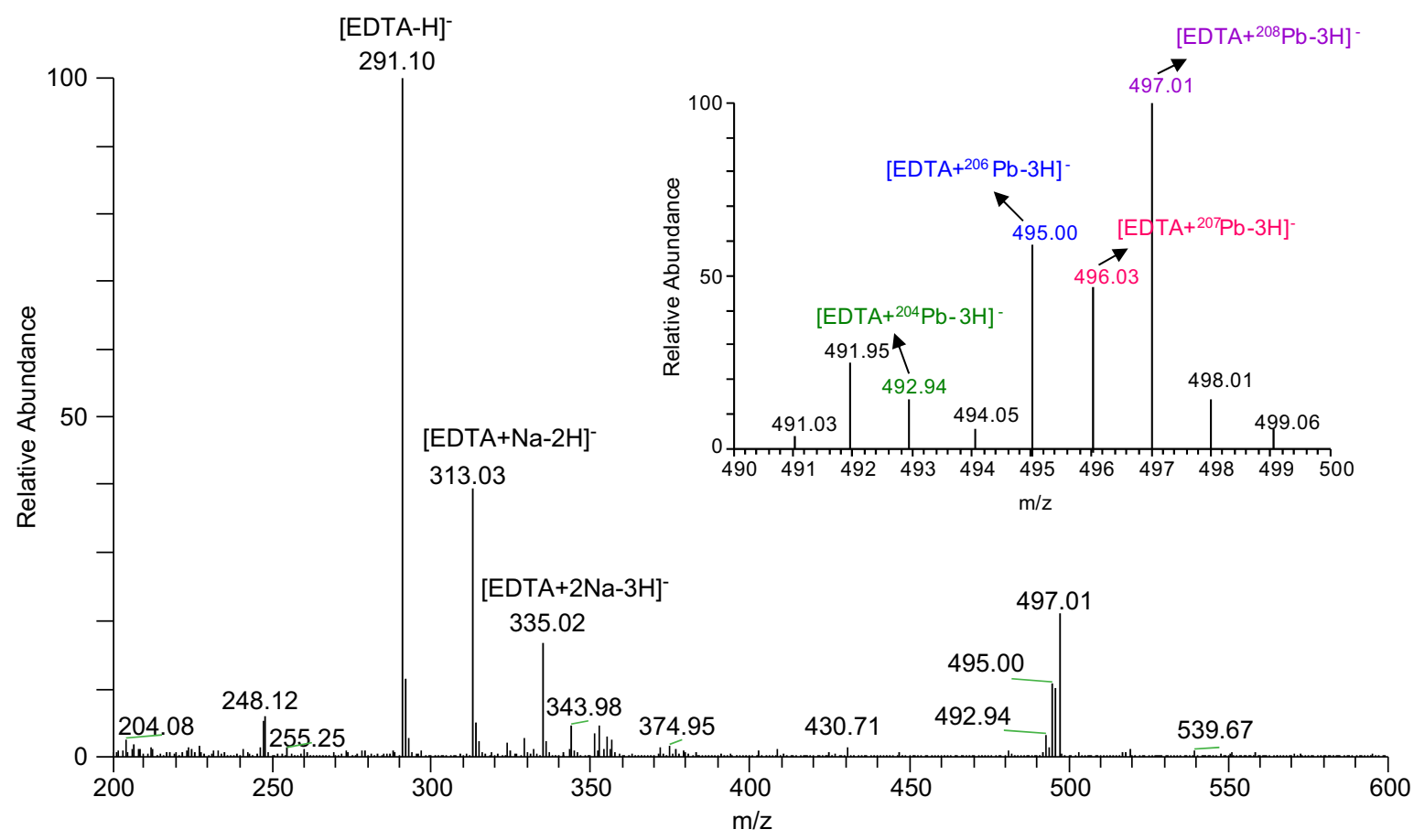

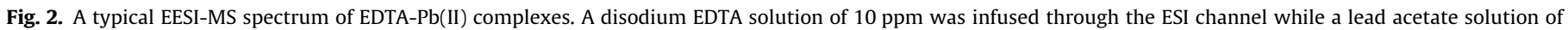
$5 \mathrm{ppm}$ was infused in the sample channel.

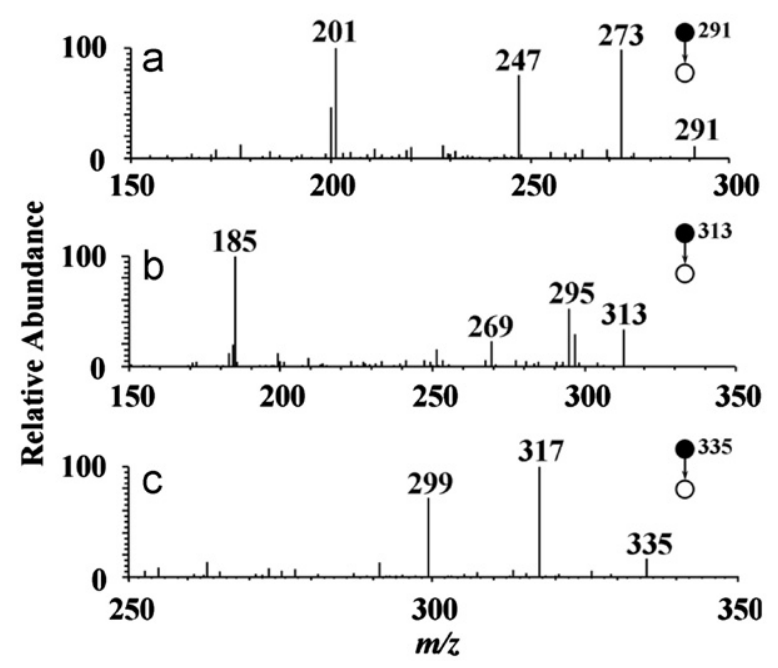

Fig. 3. Qualitative characterization of EDTA signals observed in the EESI-MS/MS spectra of (a) deprotonated EDTA of $m / z 291$; (b) [EDTA+Na-2H] $]^{-}$ions of $m / z 313$; (c) $[\text { EDTA }+2 \mathrm{Na}-3 \mathrm{H}]^{-}$ions of $m / z 335$.

EDTA primarily generated by the ESI channel. The assignment was based on tandem mass spectrum of the precursor ions of $m / z 291$ (Fig. 3a). The major fragments were those at $m / z 273,247$, and 201; the precursor ions $(m / z 291)$ lost $\mathrm{H}_{2} \mathrm{O}$ to produce the fragment ions at $m / z 273$, and lost $\mathrm{CO}_{2}$ to yield the fragments at $m / z$ 247. The peak at $m / z 201$ was generated by the loss of $\mathrm{CO}_{2}$, $\mathrm{H}_{2} \mathrm{O}$, and $\mathrm{CO}$ from the precursor ions $(\mathrm{m} / z$ 291). The peaks at $m / z$ 313.03 and 335.02 in Fig. 2 were due to [EDTA $+\mathrm{Na}-2 \mathrm{H}]^{-}$and $[\text { EDTA }+2 \mathrm{Na}-3 \mathrm{H}]^{-}$, respectively. In Fig. $3 \mathrm{~b}$, the precursor ions [EDTA+Na-2H] $]^{-}$lost $\mathrm{H}_{2} \mathrm{O}$ to generate the peak at $m / z 295$, and lost $\mathrm{CO}_{2}$ to form the peak at $m / z 269$ which further lost $\mathrm{Na}, \mathrm{CO}_{2}$, and $\mathrm{HO}$ to yield the peak at $m / z$ 185. [EDTA $+2 \mathrm{Na}-3 \mathrm{H}]^{-}$in Fig. $3 \mathrm{c}$ lost $\mathrm{H}_{2} \mathrm{O}$ and $2\left(\mathrm{H}_{2} \mathrm{O}\right)$ to produce the product ions with $m / z 317$ and 299, respectively. The fragmentation patterns were in consistent with those previously observed [60]. In addition, as shown in Fig. S1, we collected the EESI-MS ${ }^{3}$ spectra of [EDTA-H $]^{-},[\text {EDTA }+\mathrm{Na}-2 \mathrm{H}]^{-}$, and $[\mathrm{EDTA}+2 \mathrm{Na}-3 \mathrm{H}]^{-}$, targeting the peaks at $\mathrm{m} / \mathrm{z} 273$ (from precursor ions at $m / z 291$ in Fig. 3a), 185 (from precursor ions at $m / z 313$ in Fig. 3b), and 317 (from precursor ions at $m / z 335$ in Fig. 3c), respectively. These data confirmed the existence of primary EDTA ions generated by the ESI channel which were expected to ionize the neutral sample droplets in the EESI source.

Lead has four major natural isotopes: ${ }^{208} \mathrm{~Pb}$ with a natural abundance of $52.4 \%,{ }^{207} \mathrm{~Pb}$ with a natural abundance of $22.1 \%$, ${ }^{206} \mathrm{~Pb}$ with a natural abundance of $24.1 \%$, and ${ }^{204} \mathrm{~Pb}$ with a natural abundance of $1.4 \%$. The inset in Fig. 2 showed the amplified view of the MS spectral region between $m / z 490$ and 500 . The intensity ratio of peaks at $m / z 497,496$, and 495 was 1:0.49:0.60, which approximately agreed with the lead natural isotopic ratio (1:0.42:0.46) although our experimental values were higher than the theoretical estimate [61]. In addition, we found that the peak at $m / z 493$ was not very stable especially when analyzing complex samples, and an example of a high peak collected in our experiments was shown in Fig. 2. Although further studies are necessary, one of the possible reasons for the isotopic ratio difference is that EESI has a different ionization mechanism than that of ESI. The isotopic ratio in this study was measured in the liquid phase by EESI where solvent-dependent extractive process plays an important role [59], while the previous study was conducted by ESI in the gas phase [61]. The peak at $m / z 497$ was tentatively assigned to $\left[\text { EDTA }+{ }^{208} \mathrm{~Pb}-3 \mathrm{H}\right]^{-}$. This assignment was further confirmed by tandem mass spectrometry. Fig. 4a showed the EESI tandem mass spectrum of the precursor ions at $m / z 497$, which lost $\mathrm{H}_{2} \mathrm{O}$ to produce the peak at $m / z 479$, lost $\mathrm{CO}_{2}$ to yield the peak at $m / z 453$, and lost $2\left(\mathrm{CO}_{2}\right)$ to generate the peak at $\mathrm{m} / z$ 409. In the EESI-MS ${ }^{3}$ spectrum (Fig. 5a), the $\mathrm{m} / \mathrm{z} 479$ ion was isolated and then lost $\mathrm{CO}_{2}$ and $\mathrm{CO}$ consecutively to generate ions at $m / z 435$ and those at $m / z$ 407. Similarly, the peaks at $m / z 496$ and 495 in Fig. 2 were assigned to $\left[\mathrm{EDTA}+{ }^{207} \mathrm{~Pb}-3 \mathrm{H}\right]^{-}$and $\left[\mathrm{EDTA}+{ }^{206} \mathrm{~Pb}-3 \mathrm{H}\right]^{-}$, respectively. In Figs. $4 b-4 c$ and $5 b-5 c$, the same fragmentation patterns were observed compared to that of $\left[E D T A+{ }^{208} \mathrm{~Pb}-3 \mathrm{H}\right]^{-}$in 


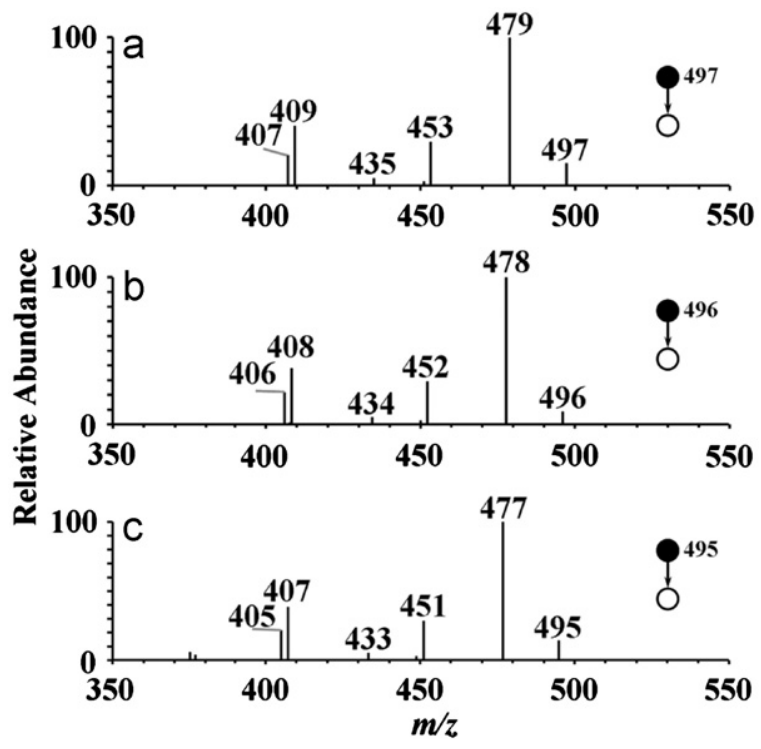

Fig. 4. EESI-MS/MS spectra of anions of EDTA-Pb(II) complexes. (a) Anions of EDTA- ${ }^{208} \mathrm{~Pb}$ complex of $\mathrm{m} / \mathrm{z} 497$; (b) anions of EDTA- ${ }^{207} \mathrm{~Pb}$ complex of $\mathrm{m} / \mathrm{z} 496$, showing the same fragmentation pattern observed in Fig. 4a; (c) anions of EDTA $-{ }^{206} \mathrm{~Pb}$ complex of $m / z 495$, showing the same fragmentation pattern observed in Figs. $4 \mathrm{a}$ and $4 \mathrm{~b}$.

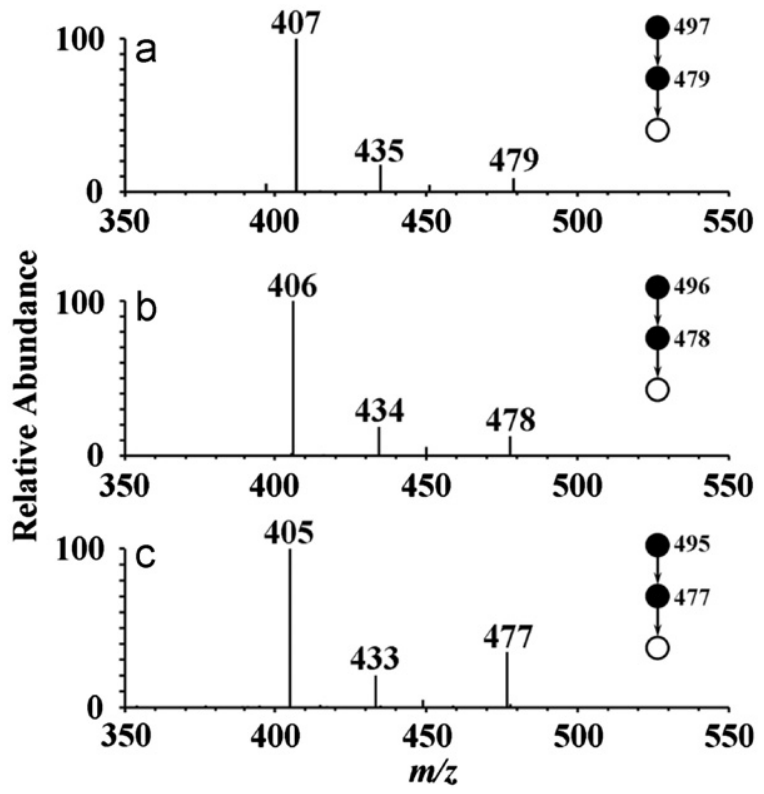

Fig. 5. EESI-MS ${ }^{3}$ spectra of anions of EDTA-Pb complexes. (a) Anions of EDTA- ${ }^{208} \mathrm{~Pb}$ complexes; (b) anions of EDTA- ${ }^{207} \mathrm{~Pb}$ complex of $m / z 496$, showing the same fragmentation pattern observed in Fig. 5a; (c) anions of EDTA- ${ }^{206} \mathrm{~Pb}$ complex of $m / z$ 495, showing the same fragmentation pattern observed in Fig. 5a and $5 \mathrm{~b}$.

that the precursor ions lost $\mathrm{H}_{2} \mathrm{O}, \mathrm{CO}_{2}, 2\left(\mathrm{CO}_{2}\right)$ in EESI-MS/MS experiments and lost $\mathrm{CO}_{2}$ and $\mathrm{CO}$ consecutively in EESI-MS ${ }^{3}$ spectra. Therefore, the reported data confirmed the successful detection and identification of EDTA-Pb(II) complexes using EESI.

More interestingly, we found that the peak at $m / z 248.12$ (Fig. 2) could be due to the doubly charged [EDTA $\left.+{ }^{208} \mathrm{~Pb}-4 \mathrm{H}\right]^{2-}$ complex. As shown in Fig. S2, [EDTA $\left.+{ }^{208} \mathrm{~Pb}-4 \mathrm{H}\right]^{2-}$ ions at $m / z 248$ lost $2\left(\mathrm{H}_{2} \mathrm{O}\right)$ to produce the peak at $m / z 230$, and they lost $\mathrm{CH}_{2} \mathrm{COO}$ to generate the peak at $m / z 219$ in the EESI-MS/MS spectrum. Similarly, the peaks at $m / z 145,156$, and 167 were assigned to [EDTA-2H] ${ }^{2-}$, $[\mathrm{EDTA}+\mathrm{Na}-3 \mathrm{H}]^{2-}$, and $[\mathrm{EDTA}+2 \mathrm{Na}-4 \mathrm{H}]^{2-}$ based on the tandem mass spectrometry data (not shown). EDTA has the ability to chelate many metal ions to form 1:1 EDTA-to-metal complexes; for the case of EDTA-Pb(II) complex the $\log K_{f}$ is 1018 , which means that the interaction between EDTA anions and $\mathrm{Pb}(\mathrm{II})$ ions should be very strong. The commonly used EDTA compound is its disodium salt, and when dissolved in water the species of [EDTA-H $]^{-}$and [EDTA-2H $]^{2-}$ can be observed and detected by ESI-MS [62], which fits well with our results using EESI-MS. [EDTA $+\mathrm{Pb}-3 \mathrm{H}]^{-}$and $[\mathrm{EDTA}+\mathrm{Pb}-4 \mathrm{H}]^{2-}$ ions in aqueous solutions have been observed by NMR spectroscopy [63]. The gas phase ions of [EDTA $+\mathrm{Pb}-3 \mathrm{H}]^{-}$and $[\mathrm{EDTA}+\mathrm{Pb}-4 \mathrm{H}]^{2-}$ were also previously characterized using ESI-MS and ICP-MS $[61,62,64]$. With the presence of $\mathrm{Pb}(\mathrm{II})$ ions, EESI-MS readily detected the complex ions of [EDTA $+\mathrm{Pb}-3 \mathrm{H}]^{-}$and $[\mathrm{EDTA}+\mathrm{Pb}-4 \mathrm{H}]^{2-}$ in this study. We also noticed that the intensity of [EDTA $+\mathrm{Pb}-4 \mathrm{H}]^{2-}$ ions was smaller than that of the $[\mathrm{EDTA}+\mathrm{Pb}-3 \mathrm{H}]^{-}$ions. This difference showed up probably because multiply charged anions are unstable due to the strong Coulomb repulsion between excess charges.

\subsection{Direct and semi-quantitative measurement using EESI}

To improve selectivity and reliability, $\mathrm{Pb}$ (II) quantification was based on the characteristic fragments at $\mathrm{m} / \mathrm{z} 407$ in the EESI-MS ${ }^{3}$ experiments of $\left[\text { EDTA }+{ }^{208} \mathrm{~Pb}-3 \mathrm{H}\right]^{-}$ions, which were generated from the online ion/molecule reaction in the EESI source. When analyzing samples with complex matrices, we found that EESI-MS ${ }^{2}$ spectra were generally noisy than EESI-MS ${ }^{3}$ spectra. The quantitative performance of EESI-MS ${ }^{3}$ was better than that of EESI-MS ${ }^{2}$ in this study, except that the detection limit was a little bit worse. Therefore, we decided to use EESI-MS ${ }^{3}$ to carry out further experiments. Semi-quantitative measurement of lead was performed using several water-based samples (e.g., deionized water, tap water, lake water, beer, tea brew, Coco-cola, etc.) spiked with trace amounts of lead ( $1 \mathrm{ppt}-100 \mathrm{ppb})$. Fig. 6a showed the external calibration curve for quantifying $\mathrm{Pb}(\mathrm{II})$ spiked in deionized water, and the curve had a linear signal response range of 1-100 ppt. In this concentration range, the response curve could be expressed by an equation $y\left(\times 10^{3} \mathrm{cps}\right)=0.0019 x(\mathrm{ppt})+0.1444\left(R^{2}=0.9874\right)$. To be noticed, for each data point in Fig. 6a ten measurements were repeated and the relative standard deviation (RSD) was between $4.6 \%$ and $7.6 \%$. The RSD values for the five data points (in the order of spiked concentration) in Fig. 6a were 7.6\%, 4.9\%, 6.5\%, 7.6\%, and $4.6 \%$ with the corresponding standard deviation values $\left(\times 10^{3} \mathrm{cps}\right)$ of $0.010,0.008,0.011,0.018$, and 0.015 . Although the signal intensities were relatively low, the signal-to-noise ratio was good $(\geq 30)$. As shown in Table 1, the limit of detection (LOD) of $\mathrm{Pb}(\mathrm{II})$ in deionized water was estimated to be $3.0 \times 10^{-14} \mathrm{~g} / \mathrm{mL}$. In addition, pure deionized water was spiked with $\mathrm{Pb}(\mathrm{Ac})_{2}$ to obtain a concentration of $5 \times 10^{-12} \mathrm{~g} / \mathrm{mL}$, and a recovery rate of $100 \%$ was achieved based on ten repeated measurements using EESI. These data proved that EESI-MS is able to directly quantify $\mathrm{Pb}$ in deionized water with acceptable precision and accuracy.

Several other aqueous liquids were selected to further challenge EESI for the direct quantitative analysis of lead. Samples were mineral water, tap water, lake water, beer, orange juice, tea brew, soft drinks, and energy drinks. Fig. S3 showed a typical EESI-MS spectrum collected from a Woolong tea sample. Table 1 summarized the major analytical results achieved by EESI-MS ${ }^{n}$ for the quantitative measurement of $\mathrm{Pb}$ (II) in these samples. The calibration curves for Nongfu Spring mineral water, Jinggang green tea, and Master Kang mineral water were shown in Fig. 6 b-d, respectively. Data were collected but not shown for the calibration curves of $\mathrm{Pb}(\mathrm{II})$ in seven other aqueous samples picked in this study. It can be clearly seen that the linear dynamic range was generally higher than two orders of magnitude. The calibration curves, with all $R^{2}$ values larger than 0.90 , had different coefficients measured from different liquid samples due to matrix 
a

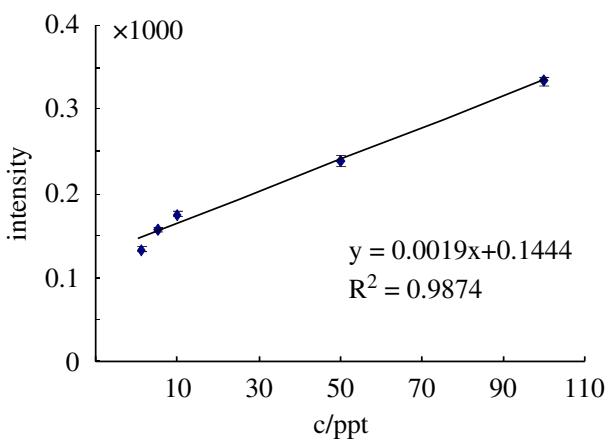

C

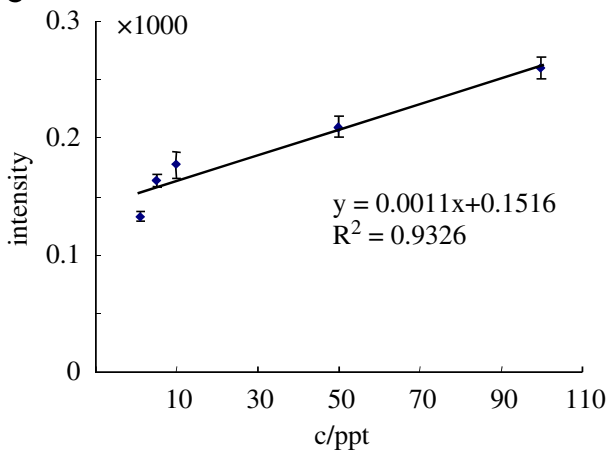

b

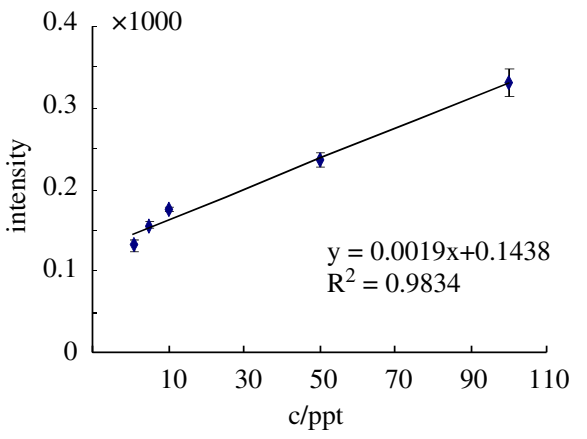

d

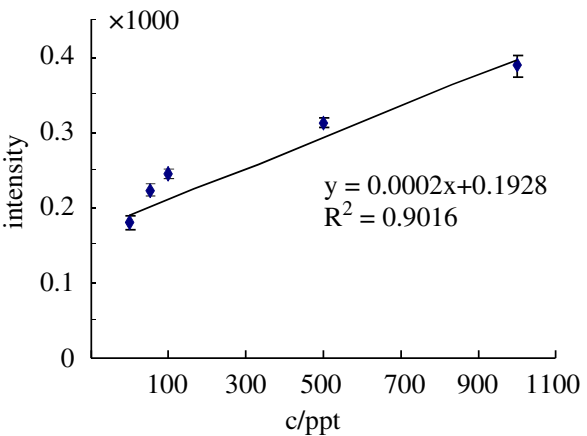

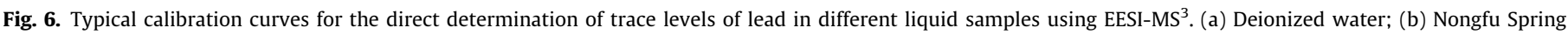
mineral water; (c) Jinggang green tea; (d) Master Kang mineral water.

Table 1

Analytical results of EESI-MS ${ }^{3}$ for the measurement of lead in aqueous liquids.

\begin{tabular}{|c|c|c|c|c|c|c|}
\hline Samples ${ }^{\mathrm{a}}$ & $\begin{array}{l}\text { Linear equation } \mathrm{y} \\
\left(\times 10^{3} \mathrm{cps}\right)=\alpha \times x(\mathrm{ppt})+\beta\end{array}$ & $R^{2}$ & $\begin{array}{l}\text { Linear dynamic range } \\
\left(\times 10^{-12} \mathrm{~g} / \mathrm{mL}\right)\end{array}$ & LOD $(\mathrm{g} / \mathrm{mL})$ & $\begin{array}{l}\text { Recovery rate } \\
\left(\%, 5.0 \times 10^{-12} \mathrm{~g} / \mathrm{mL}\right)\end{array}$ & $\operatorname{RSD}(n=10, \%)$ \\
\hline Deionized water & $y=0.0019 x+0.1444$ & 0.9874 & $1-100$ & $3.0 \times 10^{-14}$ & 100 & $4.6-7.6$ \\
\hline $\begin{array}{l}\text { Nongfu Spring mineral } \\
\text { water }\end{array}$ & $y=0.0019 x+0.1438$ & 0.9834 & $1-100$ & $3.0 \times 10^{-14}$ & 99.9 & $6.0-18.5$ \\
\hline Master Kang mineral water & $y=0.0002 x+0.1928$ & 0.9016 & $1-1000$ & $3.8 \times 10^{-14}$ & 108.2 & $7.4-13.9$ \\
\hline Tap water & $y=0.0014 x+0.1368$ & 0.9532 & $1-100$ & $3.0 \times 10^{-13}$ & 93.1 & $7.9-16.4$ \\
\hline Lake water & $y=0.0010 x+0.1869$ & 0.9829 & $1-100$ & $3.0 \times 10^{-13}$ & 123.2 & $8.9-19.1$ \\
\hline Jinggang green tea & $y=0.0011 x+0.1516$ & 0.9326 & $1-100$ & $3.2 \times 10^{-14}$ & 104.1 & $9.0-18.6$ \\
\hline Red Bull & $y=0.0012 x+0.1448$ & 0.9019 & $1-100$ & $3.0 \times 10^{-13}$ & 100.1 & $7.1-15.1$ \\
\hline Qingdao beer & $y=0.0016 x+0.1443$ & 0.9324 & $1-100$ & $2.4 \times 10^{-14}$ & 92.1 & $7.5-13.1$ \\
\hline Huiyuan orange juice & $y=0.0003 x+0.2388$ & 0.9183 & $1-100$ & $1.4 \times 10^{-14}$ & 129.0 & $5.2-14.8$ \\
\hline Woolong tea & $y=1.8 \mathrm{E}-5 x+0.1842$ & 0.9067 & $1-10000$ & $3.2 \times 10^{-14}$ & 108.6 & $6.1-14.8$ \\
\hline Coca-cola & $y=3.3 \mathrm{E}-6 x+0.1651$ & 0.9695 & $1-100000$ & $3.8 \times 10^{-14}$ & 91.5 & $7.4-16.7$ \\
\hline
\end{tabular}

a No lead content was found from the blank samples tested in this study.

effect. Low LOD values were obtained with a range of $1.4 \times$ $10^{-14} \mathrm{~g} / \mathrm{mL}(S / N \geq 3)$ to $3.0 \times 10^{-13} \mathrm{~g} / \mathrm{mL}(S / N \geq 3)$. For Coca-cola, this method provided the widest linear dynamic range of five orders of magnitude. This observation is a good example demonstrating that EESI does have high matrix tolerance, but matrix effect is complicated in EESI and it needs more thorough studies. As shown in Table 1 , the recovery rate $\left(5.0 \times 10^{-12} \mathrm{~g} / \mathrm{mL}\right)$ was between $91.5 \%$ and $129.0 \%$ depending on sample matrices. The RSD values were in the range of $4.6 \%$ (deionized water) to $19.1 \%$ (Lake water), showing relatively good reproducibility for measuring trace levels of lead in various liquid samples including beverages. More importantly, each measurement of a sample could be finished within $2 \mathrm{~min}$. Compared to traditional methods currently available for lead detection, EESI-MS provides a promising alternative for fast screening the presence of lead and for the semi-quantitative determination of lead in many liquid samples.
Inorganic analytes, especially those accompanied with complex matrices, are not compatible with many current ionization techniques for rapid and direct analysis. ICP-MS can be used to analyze metal compounds, but usually after extensive sample pretreatment $[31,33]$. Since ICP-MS is a classic method to detect lead [31,35,65-67], we also performed quantitative analysis of lead in various samples using ICP-MS. It was found that the performance of EESI-MS ${ }^{n}$ was comparable to that of ICP-MS for lead detection in samples with complex matrices. For example, Fig. S4 showed a typical calibration curve for ICP-MS to measure lead in Coca-Cola, with a linear dynamic range of four orders of magnitude. Similar to EESI-MS ${ }^{n}$, the LODs for ICP-MS to measure lead in different samples were generally at the level of ppt or less, which fits well with previous studies [31,35,65-67]. However, during ICP analysis, analytes, no matter whether they are organic or inorganic species, are usually broken down to elemental atoms 
for further mass spectrometric analysis or spectroscopic measurement. This destructive feature of ICP makes it difficult to obtain the speciation information of analytes such as complexes formed between metallic ions and organic ligands. Although some sample pretreatment techniques can help in speciation analysis, these steps are usually time-consuming, not to mention that they may bring impurities into analysis and that they may even change the oxidation states of analytes. In contrast, EESI-MS has high matrix tolerance which makes it possible to carry out direct analysis of $\mathrm{Pb}$ (II) in complex matrices. To be noticed, the ion/molecule reaction in the EESI source mainly happened between EDTA and $\mathrm{Pb}(\mathrm{II})$ in this study. Sample matrix containing lead in other states or organic acids that have higher affinity to lead than EDTA will induce deviations in EESI$\mathrm{MS}^{n}$ measurements, especially compared to that obtained by ICP-MS. Since this is an important issue for the development of EESI-MS towards a better analytical tool, we are planning quantitative experiments to study the matrix effect using EESI-MS ${ }^{n}$ to detect lead in samples with complex matrices. The ion/molecule reaction generating EDTA-Pb(II) complexes can occur online in the EESI source, and it does not change the speciation of lead in its original samples. This potentially enables EESI to be used as a real-time screening tool with high throughput capability. Last but not the least, our data showed that EESI-MS ${ }^{3}$ can semi-quantitatively detect lead with its original speciation in many kinds of samples with complex matrices. Meanwhile, direct infusion ESI is often not recommended for the detection of lead in complex samples due to matrix effect and residue deposition problems on the ESI tip. While noticing the perspectives of the complementary application of solid-state Raman spectroscopy and mass spectrometry for the analysis of crystalline samples [68], in this study we observed a fast deposition of salts on the ESI tip when the complex samples spiked with lead were directly infused, and that the reproducibility of quantitative measurements was better in EESI-MS ${ }^{n}$ than that in direct-infusion ESI.

\section{Conclusions}

A sensitive approach based on EESI tandem mass spectrometry for the rapid detection of trace levels of lead in various aqueous liquids was developed. During EESI, the EDTA aqueous solution was electrosprayed to produce primary ions which combined with the neutral droplets containing $\mathrm{Pb}$ (II) to form anions of EDTA-Pb(II) complexes. The fragmentation patterns in tandem mass spectrometry were examined to confirm the successful lead detection. The quantification performance of EESI-MS ${ }^{3}$ for the detection of lead in complex matrices was investigated, providing reasonable linear dynamic range, low RSDs, low LOD values, and acceptable recovery rates. Semi-quantitative analysis of lead in various aqueous liquid samples has been demonstrated, each with a 2 min analysis time. Our experimental data proved that EESI-MS ${ }^{n}$ provides a semiquantitative approach for the fast, sensitive, and selective detection of toxic lead in complex matrices, showing potentially wide applications in food safety and environmental sciences.

\section{Acknowledgments}

This work was supported by Chinese National Science Foundation (No. 21005015 and No. 20827007) and Chinese National Instrumentation Program (2011YQ170067).

\section{Appendix A. Supporting information}

Supplementary data associated with this article can be found in the online version at http://dx.doi.org/10.1016/j.talanta.2012.06.048.

\section{References}

[1] A. Demayo, M.C. Taylor, K.W. Taylor, P.V. Hodson, CRC Crit. Rev. Environ Control. 12 (1982) 257-305.

[2] M. Lippmann, Environmental Toxicants: Human Exposures and Their Health Effects, Wiley-Interscience, Hoboken, 2009.

[3] L. Patrick, Altern. Med. Rev, 11 (2006) 2-22.

[4] A.R. Cohen, M.S. Trotzky, D. Pincus, Pediatrics 67 (1981) 904-906

[5] F.M. Johnson, Mutagen. Res. Rev. Mutagen. Res. 410 (1998) 123-140.

[6] T.I. Lidsky, J.S. Schneider, Brain 126 (2003) 5-19.

[7] H. Needleman, Annu. Rev. Med. 55 (2004) 209-222.

[8] N.C. Papanikolaou, E.G. Hatzidaki, S. Belivanis, G.N. Tzanakakis, A.M. Tsatsakis, Med. Sci. Monit. 11 (2005) Ra329-Ra336.

[9] H. Gurer, N. Ercal, Free Radic. Biol. Med. 29 (2000) 927-945.

[10] B.K. Lee, B.S. Schwartz, W. Stewart, K.D. Ahn, Occup. Environ. Med. 52 (1995) 13-19.

[11] P.E. Body, G. Inglis, P.R. Dolan, D.E. Mulcahy, Crit. Rev. Environ. Contr. 20 (1991) 299-310.

[12] P.J. Bushnell, R.J. Jaeger, Vet. Hum. Toxicol. 28 (1986) 255-261.

[13] R.M. Hicks, Chem. Biol. Interact. 5 (1972) 361-390.

[14] S.J. Pocock, M. Smith, P. Baghurst, Br. Med. J. 309 (1994) 1189-1197.

[15] X. Huo, L. Peng, X.J. Xu, L.K. Zheng, B. Qiu, Z.L. Qi, B. Zhang, D. Han, Z.X. Piao, Environ. Health Perspect. 115 (2007) 1113-1117.

[16] W.H. Luo, Y. Zhang, H. Li, Arch. Environ. Health 58 (2003) 184-187.

[17] B. Wang, J.L. Zhang, Y.S. Zhang, J.A. Qin, S.Q. Wang, K.M. He, Epidemiology 22 (2011), S283-S283.

[18] J.L. Zhang, S.Q. Wang, Proceedings of the 3rd International Academic Conference on Environmental and Occupational Medicine (2006) 69-73.

[19] K. Eisenberg, E. van Wijngaarden, Am. J. Public Health 98 (2008) 1156-1157.

[20] S.L. Gerstenberger, E.C. Gorospe, Clin. Toxicol. 46 (2008) 728-737.

[21] Anon, Lancet 261 (1951) 1147-1147.

[22] D.L. MacIntosh, C. Kabiru, K.A. Scanlon, P.B. Ryan, J. Exposure Anal. Environ. Epidemiol. 10 (2000) 196-205.

[23] T.D. Matte, D. Proops, E. Palazuelos, J. Graef, M.H. Avila, Lancet 344 (1994) 1064-1065.

[24] N. Burham, S.M. Abdel-Azeem, M.F. El-Shahat, Anal. Chim. Acta 579 (2006) 193-201.

[25] V.A. Lemos, A.L. de Carvalho, Environ. Monit. Assess. 171 (2010) 255-265.

[26] M. Rose, M. Knaggs, L. Owen, M. Baxter, J. Anal. At. Spectrom. 16 (2001) 1101-1106.

[27] Y. Yamamoto, Y. Nishino, K. Ueda, Talanta 32 (1985) 662-664.

[28] R. Gwiazda, D. Woolard, D. Smith, J. Anal. At. Spectrom. 13 (1998) 1233-1238.

[29] M. Koyama, T. Tanaka, Bunseki Kagaku 51 (2002) 815-820.

[30] H.Y. Liu, Y. Zhou, T.F. Wang, Y.J. Li, Spectrosc. Spectra. Anal. 31 (2011) 1115-1118

[31] J.A. Nunes, B.L. Batista, J.L. Rodrigues, N.M. Caldas, J.A.G. Neto, F. Barbosa, J. Toxicol. Environ. Health Part A 73 (2010) 878-887.

[32] Y. Okamoto, Fresenius J. Anal. Chem. 367 (2000) 300-305.

[33] S. Tamiya, J. Yoshinaga, Bunseki Kagaku 57 (2008) 99-104.

[34] L. Yang, J. Zeng, X.Y. Wang, Z. Wu, H.T. Chi, L. Ouyang, J.H. Zhang, J.Y. Wang, Spectrosc. Spect. Anal. 30 (2010) 518-522.

[35] Z.L. Chen, G. Owens, K.R. Kim, R. Naidu, Anal. Chim. Acta 599 (2007) 163-169.

[36] R.G. Cooks, Z. Ouyang, Z. Takats, J.M. Wiseman, Science 311 (2006) 1566-1570.

[37] Z. Takats, J.M. Wiseman, B. Gologan, R.G. Cooks, Science 306 (2004) 471-473.

[38] R.B. Cody, J.A. Laramee, H.D. Durst, Anal. Chem. 77 (2005) 2297-2302

[39] C.Y. Pierce, J.R. Barr, R.B. Cody, R.F. Massung, A.R. Woolfitt, H. Moura H.A. Thompson, F.M. Fernandez, Chem. Commun. 8 (2007) 807-809.

[40] H.W. Chen, J.H. Lai, Y.F. Zhou, Y.F. Huan, J.Q. Li, X. Zhang, Z.C. Wang, M.B. Luo, Chin. J. Anal. Chem. 35 (2007) 1233-1240.

[41] S.P. Yang, J.H. Ding, J. Zheng, B. Hu, J.Q. Li, H.W. Chen, Z.Q. Zhou, X.L. Qiao, Anal. Chem. 81 (2009) 2426-2436.

[42] H. Chen, B. Hu, X. Zhang, Chin. J. Anal. Chem. 38 (2010) 1069-1088.

[43] J.D. Harper, N.A. Charipar, C.C. Mulligan, X. Zhang, R.G. Cooks, Z. Ouyang, Anal. Chem. 80 (2008) 9097-9104.

[44] Y. Zhang, X. Ma, S. Zhang, C. Yang, Z. Ouyang, X. Zhang, Analyst 134 (2009) $176-181$.

[45] R. Haddad, R. Sparrapan, M.N. Eberlin, Rapid Commun. Mass Spectrom. 20 (2006) 2901-2905.

[46] G.A. Harris, A.S. Galhena, F.M. Fernandez, Anal. Chem. 83 (2011) 4508-4538

[47] H.W. Chen, G. Gamez, R. Zenobi, J. Am. Soc. Mass Spectrom. 20 (2009) 1947-1963.

[48] R.M. Alberici, R.C. Simas, G.B. Sanvido, W. Romao, P.M. Lalli, M. Benassi, I.B.S. Cunha, M.N. Eberlin, Anal. Bioanal. Chem. 398 (2010) 265-294.

[49] H.W. Gu, H.W. Chen, Z.Z. Pan, A.U. Jackson, N. Talaty, B.W. Xi, C. Kissinger, C. Duda, D. Mann, D. Raftery, R.G. Cooks, Anal. Chem. 79 (2007) 89-97.

[50] H. Chen, R. Zenobi, Chimia 61 (2007) 843-843.

[51] H. Chen, S. Yang, A. Wortmann, R. Zenobi, Angew. Chem. Int. Ed. 46 (2007) 7591-7594.

[52] H.W. Gu, S.P. Yang, J.Q. Li, B. Hu, H.W. Chen, L.L. Zhang, Q. Fei, Analyst 135 (2010) 779-788.

[53] H.W. Gu, B. Hu, J.Q. Li, S.P. Yang, J. Han, H.W. Chen, Analyst 135 (2010) 1259-1267.

[54] H.W. Chen, S.P. Yang, M. Li, B. Hu, J.Q. Li, J. Wang, Angew. Chem. Int. Ed. 49 (2010) 3053-3056. 
[55] M.B. Luo, B. Hu, X. Zhang, D.F. Peng, H.W. Chen, L.L. Zhang, Y.F. Huan, Anal. Chem. 82 (2010) 282-289.

[56] H. Chen, A. Venter, R.G. Cooks, Chem. Commun. 19 (2006) 2042-2044.

[57] B. Hu, X.J. Peng, S.P. Yang, H.W. Gu, H.W. Chen, Y.F. Huan, T.T. Zhang, X.L. Qiao, J. Am. Soc. Mass Spectrom. 21 (2010) 290-293.

[58] J. Ding, H. Gu, S. Yang, M. Li, J. Li, H. Chen, Anal. Chem. 81 (2009) 8632-8638.

[59] W.S. Law, R. Wang, B. Hu, C. Berchtold, L. Meier, H.W. Chen, R. Zenobi, Anal. Chem. 82 (2010) 4494-4500.

[60] R. Fingerhut, T. Dame, B. Olgemoller, Eur. J. Pediatr. 168 (2009) 553-558.

[61] Z.L. Chen, Q. Sun, Y.F. Xi, G. Owens, J. Sep. Sci. 31 (2008) 3796-3802.

[62] R.L. Sheppard, J. Henion, Anal. Chem. 69 (1997) 2901-2907.
[63] H.A. Godwin, E.S. Claudio, M.A. ter Horst, C.E. Forde, C.L. Stern, M.K. Zart, Inorg. Chem. 39 (2000) 1391-1397.

[64] A.R.S. Ross, M.G. Ikonomou, J.A.J. Thompson, K.J. Orians, Anal. Chem. 70 (1998) 2225-2235.

[65] A.J.R. Kent, Geostand. Geoanal. Res. 32 (2008) 129-147.

[66] J.C.W. Lam, K.K. Chan, Y.C. Yip, W.F. Tong, D.W.M. Sin, Food Chem. 121 (2010) 552-560.

[67] D. Baralkiewicz, M. Kozka, A. Piechalak, B. Tomaszewska, P. Sobczak, Talanta 79 (2009) 493-498.

[68] B.B. Ivanova, M. Spiteller, Talanta 94 (2012) 9-21. 